American Journal of Applied Sciences 6 (2): 296-308, 2009

ISSN 1546-9239

(C) 2009 Science Publications

\title{
Characterization of the Fracture Toughness of the Concrete Mortars Exposed to Elevated Temperatures
}

\author{
${ }^{1,2}$ S. Djaknoun, ${ }^{1}$ A. Ahmed Benyahia and ${ }^{2}$ E. Ouedraogo \\ ${ }^{1}$ Laboratoire de Mécanique avancée (LMA), FGM\&GP de L'USTHB, BP32 \\ ${ }^{2}$ Laboratoire Sols Solides Structures-Risques, Domaine Universitaire BP53, \\ 38041 Grenoble CEDEX 09 France
}

\begin{abstract}
The main objective of this research was the characterisation of the fracture toughness of concrete mortars exposed to high temperatures by using notched specimens in three point bending tests. The specimens have different lengths and were heated at different temperatures ranging from room temperature up to $900^{\circ} \mathrm{C}$. The experimental test results obtained are closed with those reported by the literature, it shows that beyond approximately $300^{\circ} \mathrm{C}$, the fracture loads decrease strongly with the rise in heating temperature. However, between the room temperature $\left(25^{\circ} \mathrm{C}\right)$ and $300^{\circ} \mathrm{C}$, we recorded an increase of the fracture load. Two methods using the experimental critical load were applied to calculate the fracture toughness of concrete mortars: an analytical method based on the mechanics of continuous medium theory and a numerical approach using finite elements method. The numerical modelling has then been validated, discussed and compared with analytical solution. Comparison between the experimental results and the theory predictions was quite good.
\end{abstract}

Key words: High performance concrete, toughness, temperature

\section{INTRODUCTION}

The elastic linear mechanics of fracture (MLER) is a usual theory for analysing the fracture of metals or brittle materials such as glass or ceramics ${ }^{[1]}$. All the phenomena of damage are supposed to be concentrated at the tip crack. As for the nonlinear mechanics of fracture (MNLR), it is supposed the existence of «fracture process zone» $(\mathrm{FPZ})^{[2]}$. Indeed, the damage mechanics and the MNLR were developed to solve the fracture problems within materials having a softening behaviour. However, the concepts of the MNLR and MLER can be used to solve the problem of the crack initiation.

Although concrete is a composite material, its mechanical performance did not reflect the simple theory of composites. This is expressed by the typical stress-strain curve of concrete and its constituent materials (cement paste and aggregates) as shown in Fig. 1. While both the cement paste and the aggregates have linear elastic behaviour up to $80 \%$ of their ultimate strength, concrete begins to deviate to non- linear behaviour when the applied stresses reach 40$50 \%$ of its ultimate capacity. The non-linear (inelastic) behaviour of concrete under stress can be explained by defining concrete as a three phase heterogeneous material, the cement paste, the aggregates and the transition zone (TZ). The TZ represents the interfacial region between the cement paste and the aggregates. The transition zone is $10-50 \mu \mathrm{m}$ thick around the aggregates particles and has less resistance than the other two phases. Because of its high porosity and low strength, microcracks can easily propagate in the transition zone while the other two phases are not Cracked. This result is the non-linear behaviour of the concrete composite. The microcraks development and propagation determines the shape of stress-strain curve of concrete under uniaxial compression. The total amount of mortar cracking is considerably less than the transition zone cracking. While the ascending part of the concrete stress-strain curve is only dependent on cracking extent in concrete, the descending part is highly influenced by the testing machine characteristics especially its stiffness.

Corresponding Author: Samira Djaknoun, Laboratoire de Mécanique avancée (LMA), FGM\&GP de L'USTHB, BP32 EL-Alia, 1611 Alger, Algérie Tel: +33 476825297 Fax: +33 476827043 


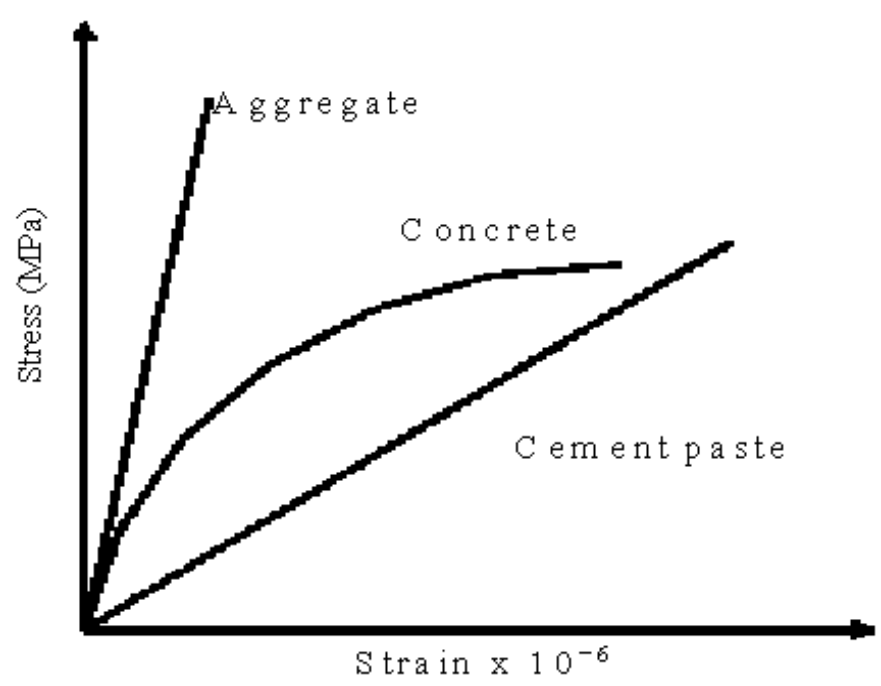

Fig. 1: Typical stress-strain of concrete and its constituent materials ${ }^{[1]}$
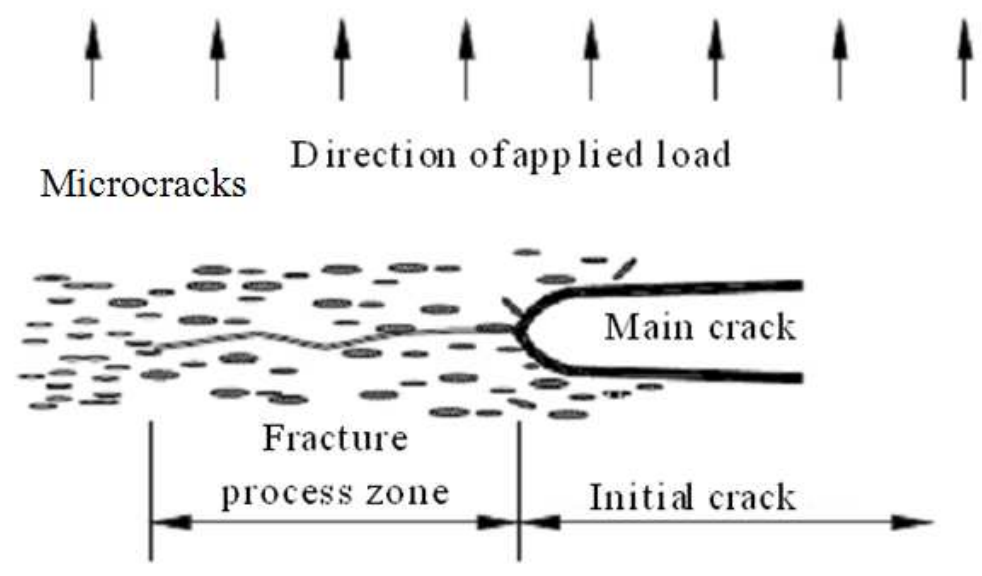

Fig. 2: Fracture process zone (FPZ) in concrete ${ }^{[3]}$

Cracking of concrete: It is also reported that some cracks are initiated at cement paste voids and then crack away of the transition zone. In the mean time, it is well established that even before the application of external stresses, microcracks already exist in the $\mathrm{TZ}$ as a result of shrinkage and thermal stresses. The number and width of these microcracks in the transition zone depend mainly on bleeding characteristics, wall effect, curing history of concrete and thermal and carbonation shrinkage extent.

\section{FRACTURE MECHANICS MODELS APPLIED TO CONCRETE}

It is well established that two basic criteria govern fracture of materials in either tension or compression.
These are the stress and the energy criteria ${ }^{[4-6]}$. Although these two criteria can explain the fracture behaviour of any material, the complexity is how to determine accurately the amount of energy consumed and the stress developed during the fracture process under specific boundary conditions ${ }^{[7]}$. In brittle materials, elastic energies are consumed in the form of surface energy with no «fracture process zone» $F P Z^{[8]}$. In ductile materials the FPZ is known as the plastic zone which can consume a considerable amount of energy, much more than the surface energy ${ }^{[9]}$. For quasi-brittle materials, a large FPZ which consumes a large amount of energy prior to failure is usually formed ahead of the crack tip. This FPZ, schematically represented in Fig. 2, provides concrete with its quasibrittle response. 
Linear elastic fracture mechanics (LEFM): The applicability of LEFM models to concrete behaviour was made experimentally and it was concluded that the Griffith concept of a critical strain-energy release is convenient. Some observations on concrete behaviour that allow the use of LEFM:

- Fracture of concrete tends to be brittle

- The strength of concrete depends on the loading rate $^{[10]}$

- The tensile strength of concrete is about $1 / 10$ of its compressive strength ${ }^{[7]}$

- Concrete and mortar are notch-sensitive

The compliance approach: One of the useful LEFM models developed for concrete is the compliance approach. This approach relates the displacement of the concrete element to the load applied through a linear relation using the cracked body stiffness or Compliance as shown in Eq. 1:

$$
\mathrm{P}=\mathrm{C} . \delta
$$

Where:

$\delta=$ The displacement

$\mathrm{P}=$ The applied load

$\mathrm{C}=$ The compliance which is a function of geometrical parameters and the crack depth

Evaluation of $\mathbf{K}_{\mathrm{IC}}$ and $\mathbf{G}_{\mathrm{IC}}$ for concrete: The critical stress intensity factor $\mathrm{K}_{\mathrm{IC}}$ is used to express the fracture toughness of concrete. $\mathrm{K}_{\mathrm{IC}}$ represents a measure of how much and how far the local stress field is altered. Equation 2 shows the mathematical expression of $\mathrm{K}_{\mathrm{IC}}$ :

$$
\mathrm{K}_{\mathrm{IC}}=\mathrm{g}(\alpha) \cdot \sigma_{\mathrm{C}} \cdot \sqrt{\pi \cdot \mathrm{a}_{\mathrm{C}}}
$$

The function $g(\alpha)$ depends on the geometry of the specimen especially loading arrangement and is provided by stress analysis, $\mathrm{a}_{\mathrm{c}}$ is the critical notch depth and $\sigma_{\mathrm{C}}$ is the critical stress of the notched section. Similarly, $\mathrm{G}_{\mathrm{IC}}$ is the critical energy release rate usually used as a LEFM parameter to express the fracture toughness. $\mathrm{G}_{\mathrm{IC}}$ can be estimated using the plane strain relation shown in Eq. 3 where both $\mathrm{K}_{\mathrm{IC}}$ and $\mathrm{E}$ are determined experimentally:

$$
\mathrm{G}_{\mathrm{IC}}=\mathrm{K}_{\mathrm{IC}}^{2}\left(\frac{1-v^{2}}{\mathrm{E}}\right)
$$

Evaluation of CTOD in concrete: The critical Crack Tip Opening Displacement (CTOD) may be evaluated by measuring the Crack Mouth Opening Displacement (CMOD) and assuming a non-linear crack profile as shown in Fig. 3. Equation 4-7 express the method that can be used to evaluate the critical CTOD:

$$
\mathrm{CMOD}=\frac{4 \sigma \cdot \mathrm{a} \cdot \mathrm{g}_{2} \cdot(\alpha)}{\mathrm{E}}
$$

Where $g_{2}(\alpha)$ is a function dependent on the specimen geometry and loading conditions ${ }^{[12]}$ :

$$
\mathrm{CTOD}=\mathrm{CMOD} \cdot \mathrm{g}_{3}(\alpha ., \eta)
$$

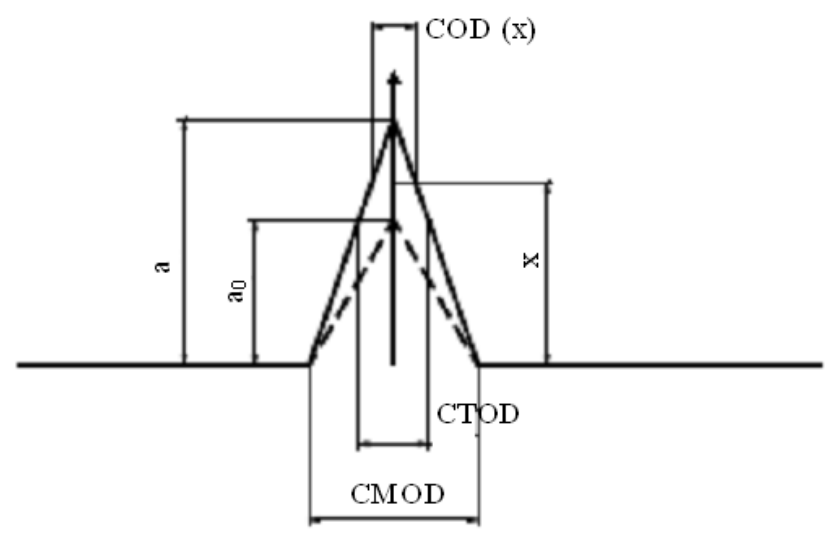

Fig. 3: Linear crack profile for the determination of CTOD measurement 


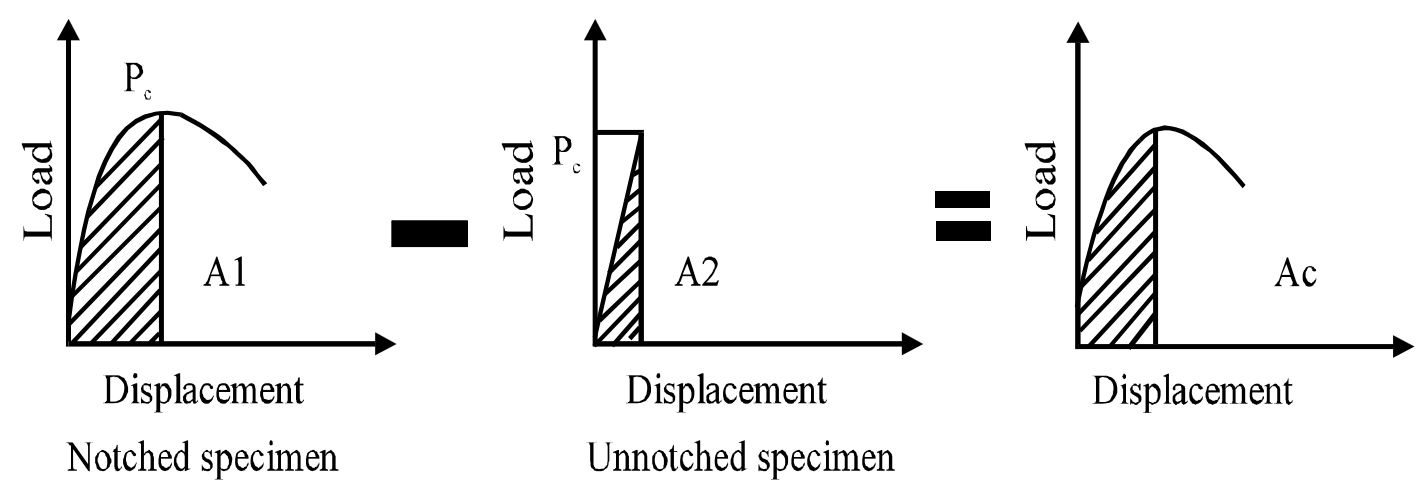

Fig. 4: Evaluation of $\mathrm{J}_{\mathrm{IC}}$ in concrete using notched and un-notched specimens

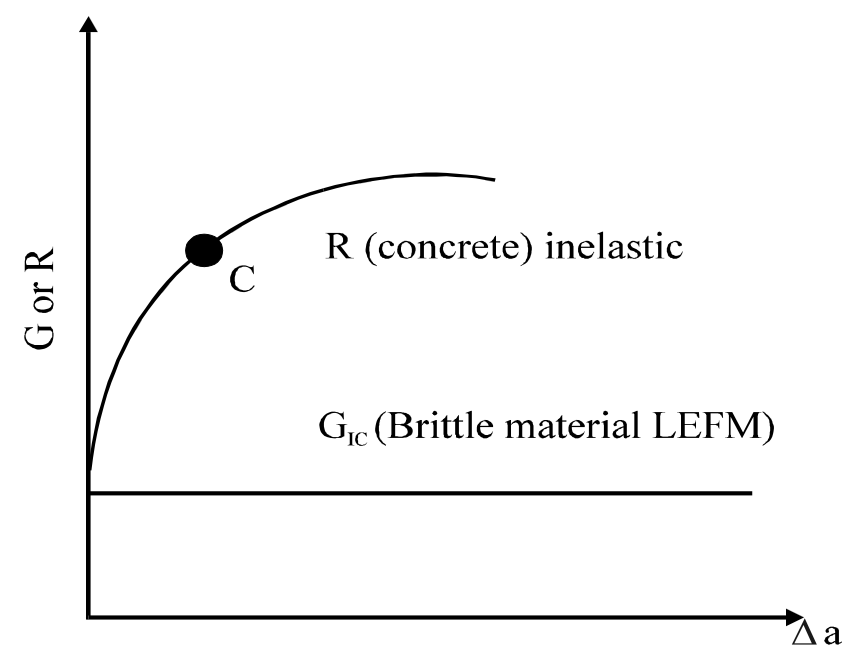

Fig. 5: Typical R-Curve of concrete

Where

$$
\begin{gathered}
g_{3}(\alpha, \eta)=\left[1-\eta^{2}+(1.081-1.149 \alpha)\left(\eta-\alpha^{2}\right)\right]^{0.5} \\
\eta=\frac{x}{a} \cdot \text { and } \cdot \alpha=\frac{a}{d}
\end{gathered}
$$

Application of the J-integral to concrete: For a nonlinear elastic body, the J-integral is defined as the energy available for crack extension. The J-integral is evaluated using the line integral defined in Eq. 8:

$$
J=\int_{\Gamma} w d y-T\left[\frac{d u}{d x}\right] d s
$$

$\mathrm{W}=$ The strain energy density

$\mathrm{T}=$ The traction vector

$\mathrm{u}=$ The displacement vector $\mathrm{ds}=$ The length increment along the contour $\Gamma$

In a pure bending test the elastic displacement of un-cracked specimen $\left(\delta_{\text {unnotched }}\right)$ will be of considerable value with respect to elastic and plastic displacement due to the crack, therefore, it should be eliminated in evaluating J. Therefore, definition of $\mathbf{J}$ in Eq. (8) is interpreted as the total absorbed energy of the cracked specimen minus its elastic energy. The estimation of $\mathrm{J}_{\mathrm{IC}}$ use the area under the load-displacement curve up to the point of maximum load only. Equation 9 can then be used to evaluate the $\mathrm{J}_{\mathrm{IC}}$ based on the loaddisplacement data measurement:

$$
\mathrm{J}_{\mathrm{IC}}=\frac{2}{\mathrm{H}_{\mathrm{C}} \mathrm{b}}\left[\mathrm{A}_{1}-\mathrm{A}_{2}\right]=\frac{2}{\mathrm{H}_{\mathrm{C}} \mathrm{b}} \mathrm{A}_{\mathrm{C}}
$$

Where $A_{2}, A_{1}$ and $A_{C}$ are the areas under the loaddisplacement curves as shown in Fig. 4. 
Application of the R-Curve to concrete: R-Curve are crack growth resistance graphs plotted as the energy release rate $G$ or crack resistance $R$ versus the crack extension. Typical R-Curve for brittle and quasi-brittle materials is presented in Fig. 5. When small inelastic FPZ exists, R-Curve can be regarded as a material property that expresses the fracture resistance to stable crack growth. The R-Curve is a useful criterion to examine the efficiency of toughening mechanisms existing in concrete. Equations 10 and 11 represent the two criteria that govern stable crack propagation using the R-Curve.

$$
\begin{array}{r}
G_{I}=R \\
\frac{\partial G_{I}}{\partial a} \leq \frac{\partial R}{\partial a}
\end{array}
$$

Under both conditions the crack propagation will be stable because both equations mean that the crack can only propagate when the load increases.

These stable crack growth conditions will govern crack propagation until the crack extension reaches its critical value $\Delta \mathrm{a}_{\mathrm{c}}$ at point $\mathrm{C}$ on the $\mathrm{R}$-curve, shown in Fig. 5. At point $C$ crack propagation will occur if $\left(\mathrm{G}_{\mathrm{I}}=\right.$ $\mathrm{R})$ and $\left(\partial \mathrm{G}_{\mathrm{I}} / \partial \mathrm{a}=\partial \mathrm{R} / \partial \mathrm{a}\right)$. After point $\mathrm{C}$, any increase of the load will result in $\left(\partial \mathrm{G}_{\mathrm{I}} / \partial \mathrm{a}\right)$ greater than $(\partial \mathrm{R} / \partial \mathrm{a})$ which will result in unstable crack propagation (failure). This explains what happens during the load displacement experiments of concrete. As the load decreases due to the increased displacement after the peak load, stable crack propagation takes place and the strain softening will be observed.

Research literature that we have undertaken shows that little work has been done for the characterization of the heated concrete toughness. Therefore, the remainder of this study will focus on a characterization of the toughness of concrete mortars exposed to elevated temperature.

\section{MATERIALS AND METHODS}

The cement used in this study is a CRS 55 (Algerian) that mineralogical characteristics are given in Table 1. A super plasticizing containing sulfonic polynaftalene (PNS) delivered in liquid form was added to mixing water and silica fume that was used is imported from Canada in the form of condensed powder that chemical composition is given in Table 2 . The chosen formulation for this mortar is given in Table 3 and the mechanical tests were performed on $(160 \times 40 \times 40) \mathrm{mm}^{3}$ notched and un-notched mortar specimens (IN 196.1). The notches length $\mathrm{a}_{0}$ has been chosen are: $15,20,25$ and $30 \mathrm{~mm}$.

\begin{tabular}{|c|c|c|c|}
\hline Phase & Mineral constituents & Percent of constituent & NA442 requirements \\
\hline \multirow[t]{5}{*}{ Clinker } & $\mathrm{C}_{3} \mathrm{~S}$ & 47 & $>65 \%$ \\
\hline & $\mathrm{C}_{2} \mathrm{~S}$ & 36 & \\
\hline & $\mathrm{C}_{3} \mathrm{~A}$ & 3 & \\
\hline & $\mathrm{C}_{4} \mathrm{AF}$ & 14 & \\
\hline & $\mathrm{CaOL}$ & -- & \\
\hline Regulator of hold & Gypse & 5 & \\
\hline Additive & Pouzzolane & 2 & $<35 \%$ \\
\hline
\end{tabular}

Table 1: Mineralogical characteristics of CRS55 cement

Table 2: Chemical composition of silica fume

\begin{tabular}{lc}
\hline Silica fume & FeSi $90 \%$ \\
\hline $\mathrm{SiO}_{2}$ & $90-96$ \\
$\mathrm{Fe}_{2} \mathrm{O}_{3}$ & $0.2-0.8$ \\
$\mathrm{Al}_{2} \mathrm{O}_{3}$ & $0.5-3.0$ \\
$\mathrm{CaO}$ & $0.1-0.5$ \\
$\mathrm{MgO}$ & $0.5-1.5$ \\
$\mathrm{Na}_{2} \mathrm{O}$ & $0.2-1.0$ \\
$\mathrm{~K}_{2} \mathrm{O}$ & $0.4-1.0$ \\
$\mathrm{C}$ & $0.5-1.4$ \\
\hline
\end{tabular}

Table 3: Mortar Formulation

\begin{tabular}{lll}
\hline Control mortar & Mortar + super plasticizer & Mortier + silica fume \\
\hline Sand: $1350 \mathrm{~g}$ & Sand: $1350 \mathrm{~g}$ & Sand: $1350 \mathrm{~g}$ \\
Cement: $450 \mathrm{~g}$ & Cement: $450 \mathrm{~g}$ & Cement: $450 \mathrm{~g}$ \\
Water: $225 \mathrm{~g}$ & Water: $135 \mathrm{~g}$ & Water: $135 \mathrm{~g}$ \\
--- & Adj.: $1.5 \%$ & Adj.: $1.5 \%$ \\
--- & -- & S F: $10 \%$ \\
w/c $=0.5$ & w/c: 0.3 & w/c $: 0.3$ \\
\hline
\end{tabular}




\section{RESULTS AND DISCUSSION}

The results obtained were of a capital importance. They showed with evidence that the fracture load decreases with the increasing length of initial notch. Through Table 4, it appears clearly that the stress intensity factor decreases with the increasing length of initial notch, thus this consolidates well the results reported in the literature. Through the diagrams of Fig. 6, it appears clearly that the fracture load given by the three-point bending tests decreases in a quasi linear evolution with the increasing initial length of notch. In Fig. 7 it can be noticed that for all initial notch lengths, the fracture load first increases with the rising heating temperature to about $300^{\circ} \mathrm{C}$. Beyond this temperature, the fracture load decreases with the rise in heating temperature. Similar results have been already reported in the literature ${ }^{[6]}$. The Fig. 8 indicates that the compression fracture load is practically comparable to the one given by three-points bending tests for the unnotched specimens Fig. 9. It should be noticed also that the loss of strength is much faster for the un-notched mortar than the notched one. Indeed, in spite of the important difference of strength in favour of the unnotched mortar for the low heating temperature, the strengths tend towards the same value (quasi null) when the temperature becomes very high. The reason is that, at high temperature damage generated in the material is so important that the strength drops to low values. In order to push of advantage the study on the behaviour of these concrete mortars exposed to elevated temperature, we were interested in the characterization of their toughness in opening mode. The $4 \times 4 \times 16$ specimens have been tested in three points bending prescribed by RILEM TC-50 ${ }^{[9]}$ with different notch lengths and exposed at different heating temperatures. Thus it has been possible to determine the critical stress intensity factor $\left(\mathrm{K}_{\mathrm{IC}}\right)$ for a concrete mortar loaded in mode I opening. In this purpose, two methods have been used: an analytical calculation based on the mechanics of continuous medium theory summarised in tables giving the $\mathrm{K}_{\mathrm{I}}$ for different geometrical forms and different stress conditions and a numerical calculations using a computer finite elements code $(\mathrm{COSMOS} / \mathrm{M} 2.0)$ in plane strain condition.

Table 4: Analytical values of $\mathrm{K}_{\mathrm{I}}$

\begin{tabular}{|c|c|c|c|c|}
\hline \multirow[b]{2}{*}{ Initial crack length (mm) } & \multicolumn{4}{|c|}{$\mathrm{K}_{\mathrm{IC}}\left(\mathrm{N} \mathrm{mm}^{-3 / 2}\right)$} \\
\hline & 15 & 20 & 25 & 30 \\
\hline \multicolumn{5}{|l|}{ Heating temperature $\left({ }^{\circ} \mathrm{C}\right)$} \\
\hline 25 & 46.36 & 41.12 & 40.10 & 50.24 \\
\hline 100 & 53.20 & 47.54 & 51.34 & 50.24 \\
\hline 300 & 66.32 & 89.32 & 76.10 & 52.88 \\
\hline 500 & 41.80 & 40.70 & 47.46 & 37.02 \\
\hline 700 & 23.80 & 19.90 & 20.44 & 17.84 \\
\hline 900 & 15.30 & 18.34 & 13.08 & 0.00 \\
\hline
\end{tabular}

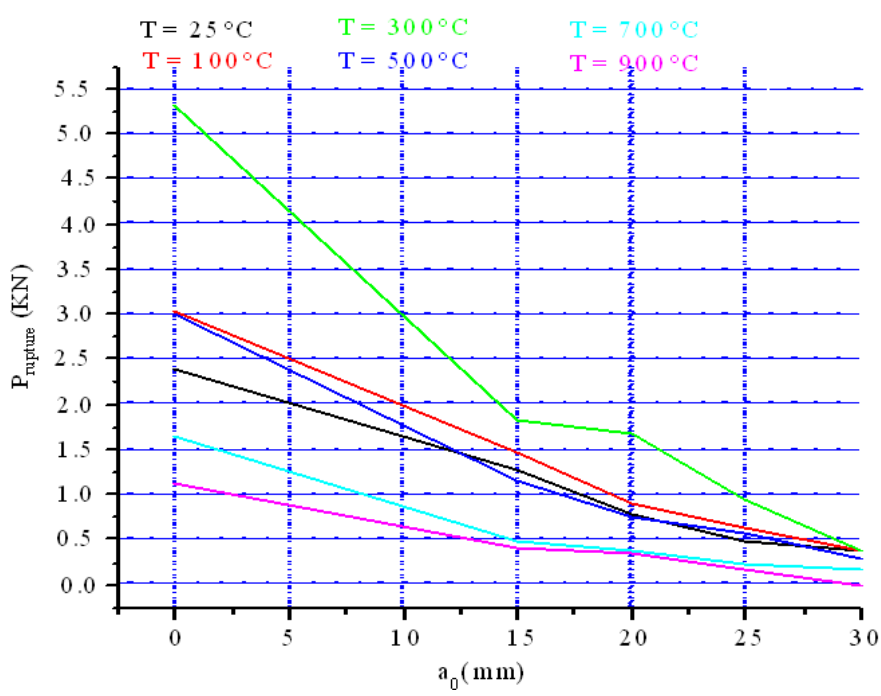

Fig. 6: Fracture load versus the initial notch length for different heating temperatures 
Am. J. Applied Sci., 6 (2): 296-308, 2009

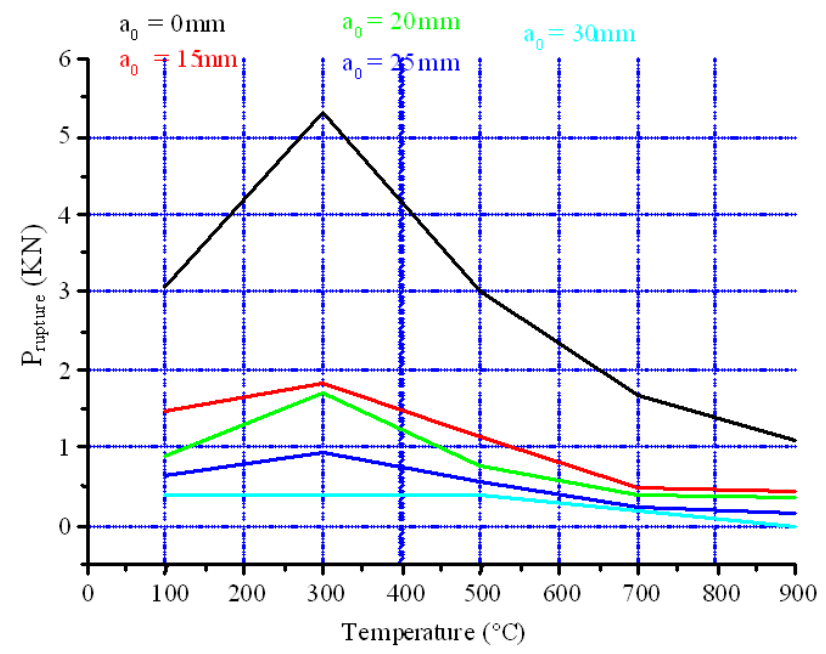

Fig. 7: Fracture load versus heating temperature for the different initial notch lengths

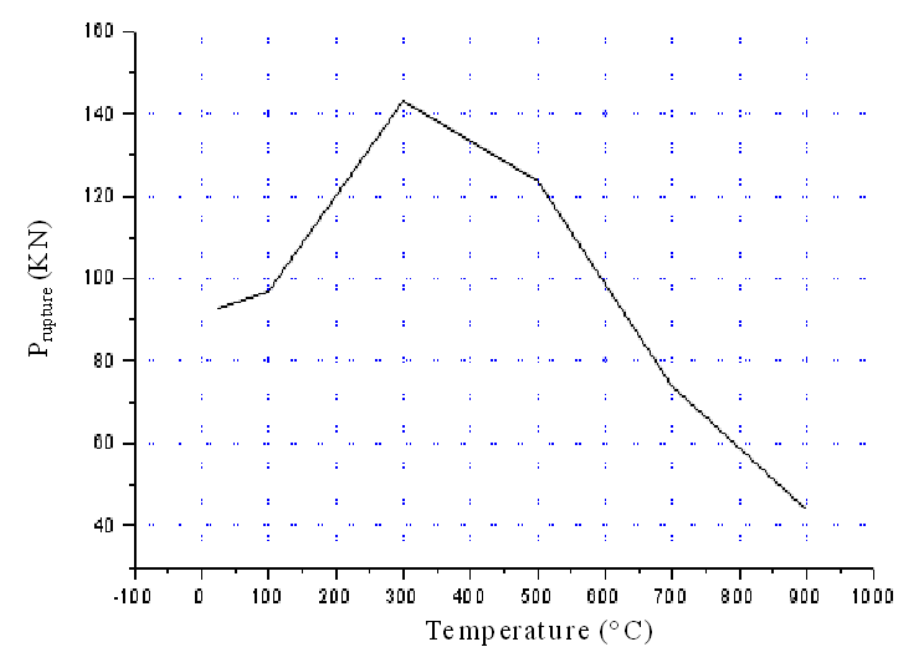

Fig. 8: Fracture load by compression versus heating temperature

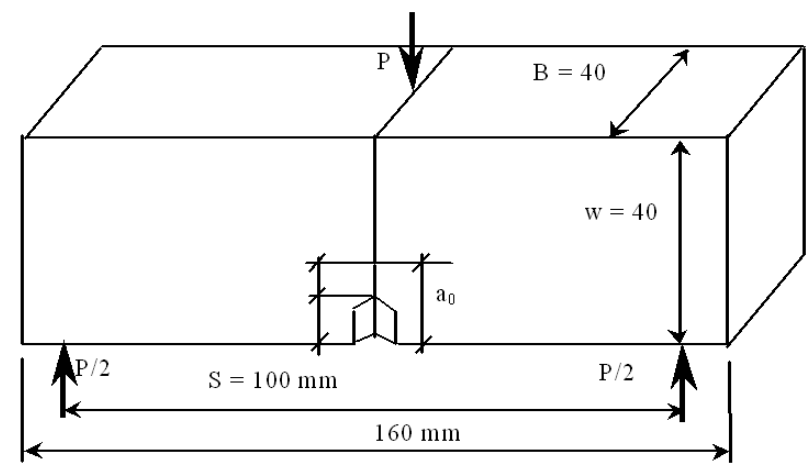

Fig. 9: Specimen used in three points bending test 
The use of notched specimens in three points bending test for the characterization of the fracture toughness $\left(\mathrm{K}_{\mathrm{IC}}\right)$ of the material in plane strain requires the verification of some dimensional values in relation with the notch length in one hand and the size of the plastic zone at the head of crack in the other hand. The analytical expression giving the stress intensity factor is reported in Eq. 12. The analytical stress intensity factor was calculated as follows:

$$
\mathrm{K}_{\mathrm{I}}=\frac{\mathrm{P} \cdot \mathrm{S}}{\mathrm{B} \cdot \mathrm{W}^{\frac{3}{2}}} . \mathrm{f}\left(\frac{\mathrm{a}_{0}}{\mathrm{~W}}\right)
$$

With:

$$
\mathrm{f}\left(\frac{\mathrm{a}_{0}}{\mathrm{~W}}\right)=\frac{3\left(\frac{\mathrm{a}_{0}}{\mathrm{~W}}\right)^{\frac{1}{2}} \cdot g\left(\frac{\mathrm{a}_{0}}{\mathrm{w}}\right)}{2\left(1+2 \frac{\mathrm{a}_{0}}{\mathrm{~W}}\right)\left(1-\frac{\mathrm{a}_{0}}{\mathrm{~W}}\right)^{\frac{3}{2}}}
$$

And

$$
g\left(\frac{a_{0}}{W}\right)=\left[1,99-\frac{a_{0}}{W}\left(1-\frac{a_{0}}{W}\right)\left(\begin{array}{l}
2,15-3,93 \\
\left(\frac{a_{0}}{W}\right)+2,7\left(\frac{a_{0}}{W}\right)^{2}
\end{array}\right)\right]
$$

The stress intensity factors for the different notch lengths and the different heating temperatures were calculated by taking into account the respective experimental loads of fracture. Their evolutions are illustrated in the diagrams of Fig. 10.

It should be noticed that the stress intensity factor $\left(\mathrm{K}_{\mathrm{IC}}\right)$ is a linear function of the applied load. It is clear then that his evolution as a function of heating temperature is similar to this of the recorded load for crack initiation.

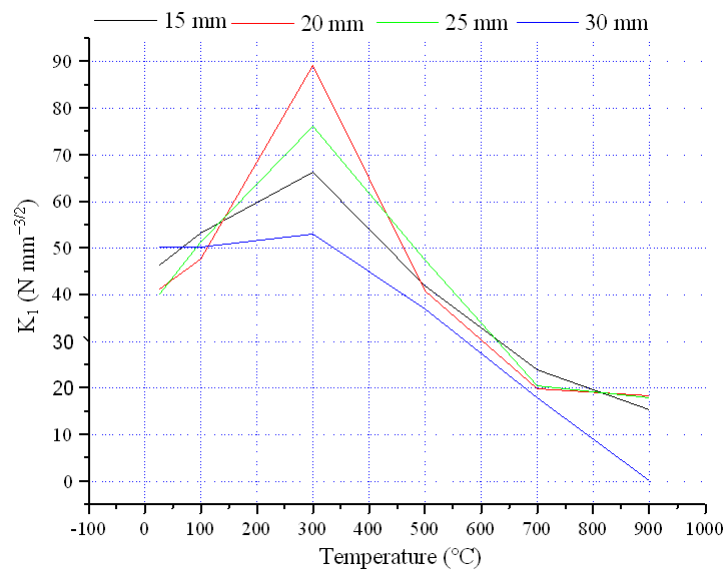

Fig. 10: Analytical stress intensity factor versus heating temperature
Indeed, it was noticed that beyond approximately $300{ }^{\circ} \mathrm{C}$, then $\left(\mathrm{K}_{\mathrm{IC}}\right)$ strongly decreases with the rising heating temperature towards zero values at about $900^{\circ} \mathrm{C}$. This means that toughness or fracture strength of a heated concrete mortar decreases when heating temperature increases. As for the increase of $\left(\mathrm{K}_{\mathrm{IC}}\right)$ between 20 and $300^{\circ} \mathrm{C}$, it is in general attributed to the resumption and acceleration of the process of hydration especially at the aggregate/cement paste interface.

In order to check the exactitude of analytical calculations carried out, we have performed calculations by a numerical approach based on the finite element method. The calculations have been undertaken with a finite elements code COSMOS/M2.0 in strain plane. For geometrical and loading symmetry reasons, only one half of the specimen has been modelled. The numerical simulation has been carried out on rectangular area $50 \mathrm{~mm}$ in length and $40 \mathrm{~mm}$ in width, the notch length $\mathrm{a}_{0}$ was variable, as shown in Fig. 11. The model was meshed into two-dimensional triangular finite elements with a node at each corner named TRIANG. The size of these elements decreases proportionally of the periphery of the specimen up to the crack, where it becomes very fine. The meshing is defined by 268 elements and 583 nodes.

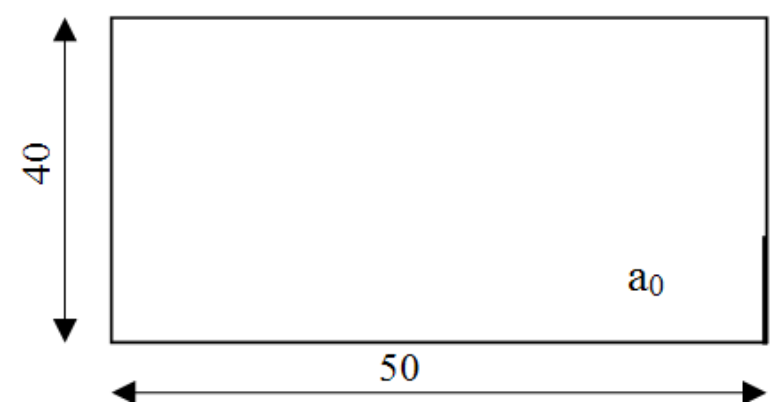

Fig. 11: Specimen half used for modelling

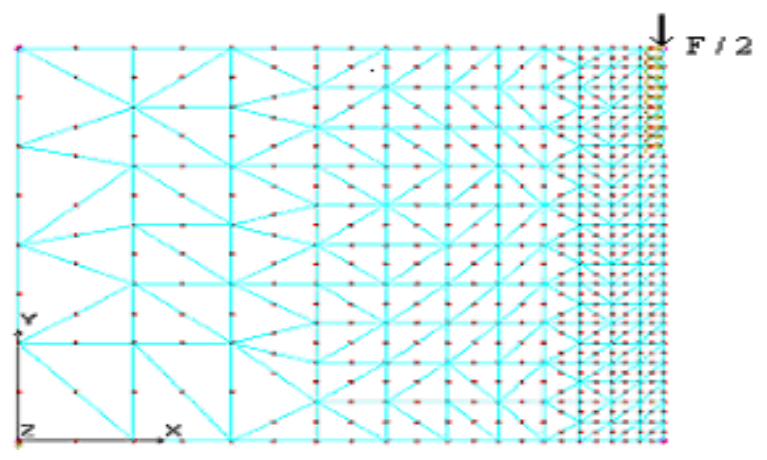

Fig. 12: Meshing of the half specimen adopted and loading conditions 
Table 5: Numerical values of $\mathrm{K}_{\mathrm{I}}$ by finite elements

\begin{tabular}{llllr}
\hline & $\mathrm{K}_{\mathrm{IC}}\left(\mathrm{N} \mathrm{mm}^{-3 / 2}\right)$ & & \\
\cline { 1 - 3 } & 15 & 20 & 25 & \multicolumn{1}{c}{30} \\
\hline Heating temperature $\left({ }^{\circ} \mathbf{C}\right)$ & & & & \\
25 & 46.80 & 42.50 & 42.40 & 52.60 \\
100 & 53.80 & 49.04 & 53.0 & 52.60 \\
300 & 67.06 & 92.10 & 80.46 & 54.18 \\
500 & 42.38 & 41.96 & 50.18 & 38.44 \\
700 & 24.80 & 20.70 & 21.62 & 18.06 \\
900 & 15.48 & 19.06 & 13.84 & 0.00 \\
\hline
\end{tabular}

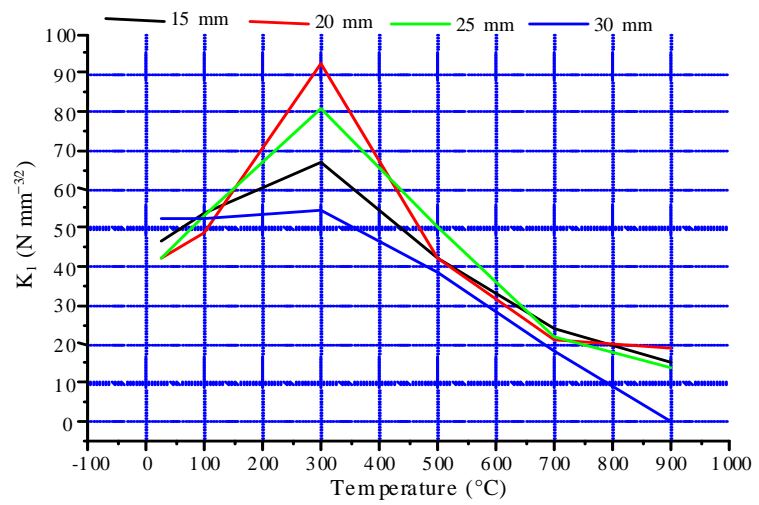

Fig. 13: Numerical stress intensity factor versus heating temperature

The loading and boundary conditions corresponding to the three-points bending test are represented in Fig. 12.

- $\quad$ The load was supposed to be specifically applied at node $\mathrm{N}^{\circ} 1$. The loads applied to the specimen during the simulation were those obtained experimentally divided by the width of the specimen.

- The symmetry of the specimen was ensured by considering all the nodes, between the crack tip and the point of load application, are blocked in the $\mathrm{X}$ axis direction using simple supports, as shown in Fig.12.

The value of intensity factor stresses calculated numerically by finite element are summarised in Table 5 and their evolution versus heating temperature is illustrated in Fig. 13.

It should be noticed that the numerical evolution of $\left(\mathrm{K}_{\mathrm{I}}\right)$ is perfectly similar of the analytical $\left(\mathrm{K}_{\mathrm{I}}\right)$ one. We proceeded to a comparison between the analytical and numerical results of the stress intensity factor $\left(\mathrm{K}_{\mathrm{I}}\right)$ in strain plane condition. For a better appreciation of the convergence of analytical and numerical results, we have chosen to represent the results of the two methods for each notch length on separate figures (Fig. 14-17).

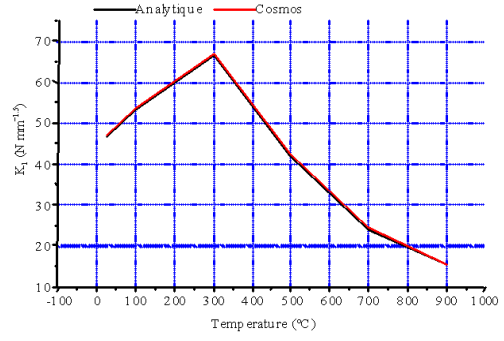

Fig. 14: Stress intensity factor versus heating temperature $\left(\mathrm{a}_{0}=15 \mathrm{~mm}\right)$

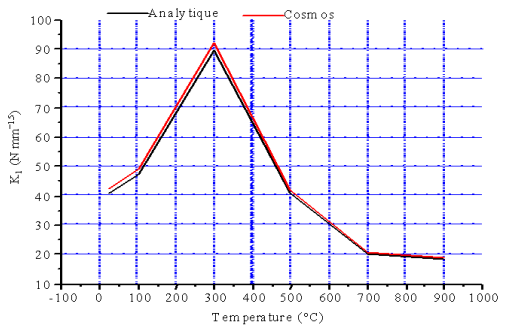

Fig. 15: Stress intensity factor versus heating temperature $\left(\mathrm{a}_{0}=20 \mathrm{~mm}\right)$

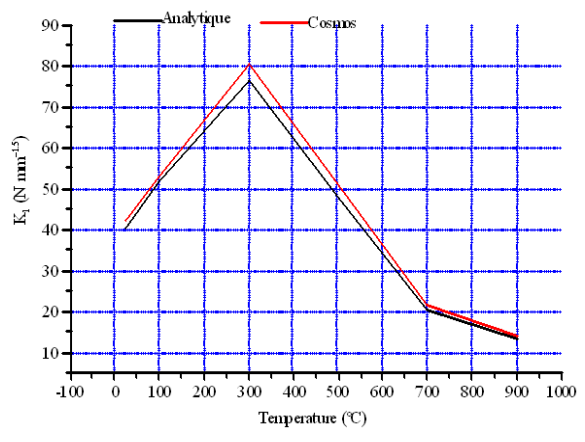

Fig. 16: Stress intensity factor versus heating temperature $\left(\mathrm{a}_{0}=25 \mathrm{~mm}\right)$

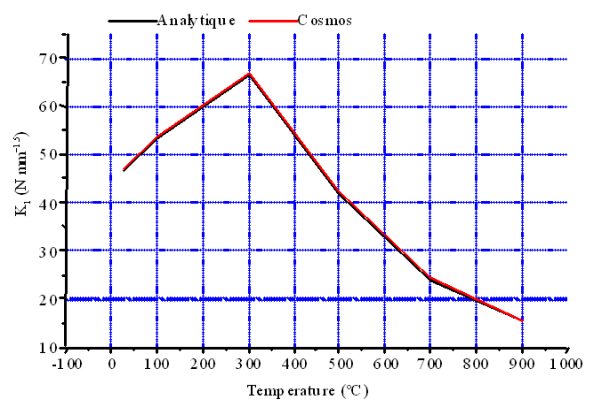

Fig. 17: Stress intensity factor versus heating temperature $\left(\mathrm{a}_{0}=30 \mathrm{~mm}\right)$ 
Am. J. Applied Sci., 6 (2): 296-308, 2009

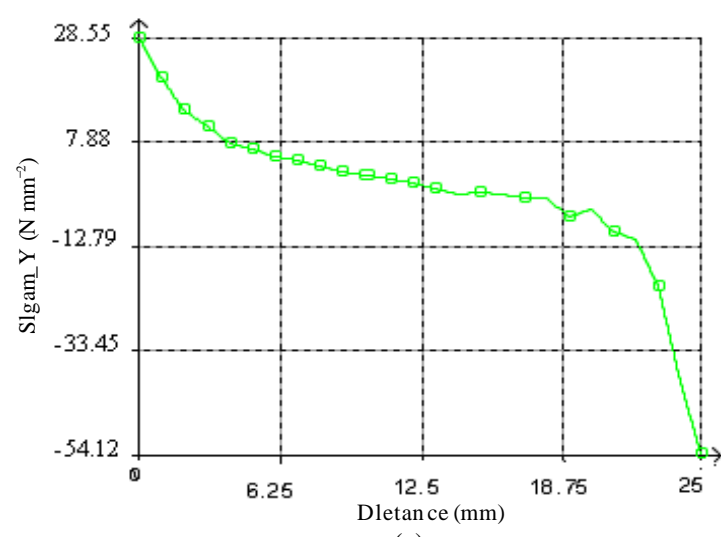

(a)

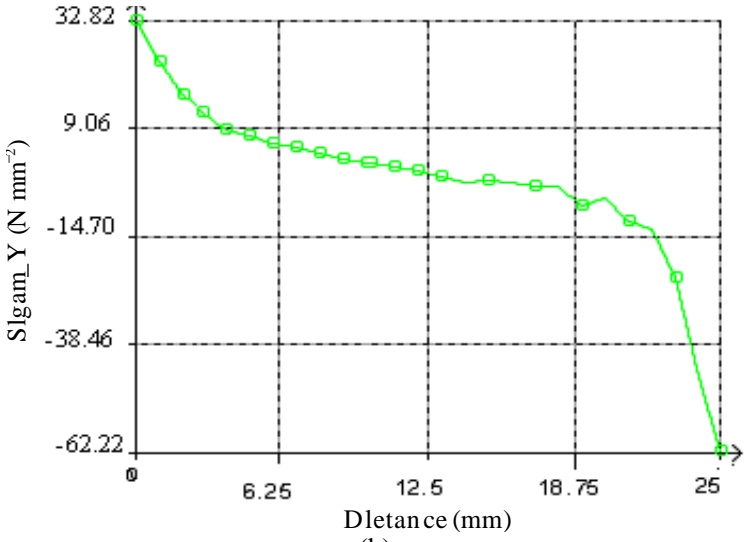

(b)

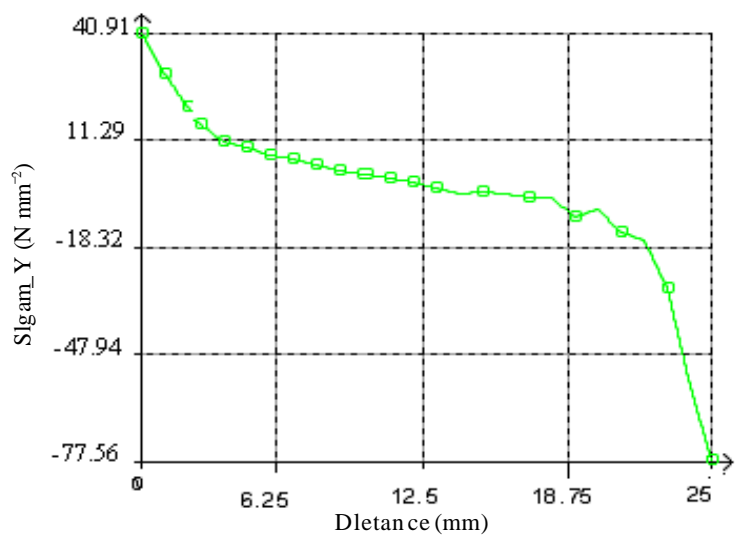

(c)

Fig. 18: Strength $\sigma_{\mathrm{Y}}$ versus y for $\mathrm{a}_{0}=15 \mathrm{~mm},(\mathrm{a}): \mathrm{T}=25^{\circ} \mathrm{C},(\mathrm{b}): \mathrm{T}=100{ }^{\circ} \mathrm{C},(\mathrm{c}): \mathrm{T}=300{ }^{\circ} \mathrm{C}$

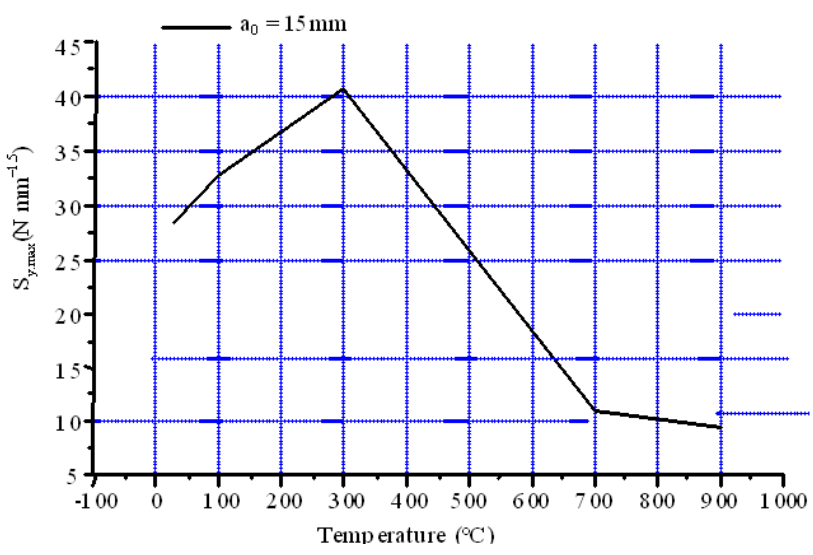

Fig. 19: Maximal strength $\sigma_{Y \max }$ for different heating temperatures with $\mathrm{a}_{0}=15 \mathrm{~mm}$

It should be noticed that for the whole of these figures, the two methods give almost the same values, the plots are quasi-identical. This consolidates us in our choice of the number of finite elements and the pertinence of numerical modeling. The evolution of the transverse strength $\sigma_{Y}$ ahead of the crack tip is illustrated in Fig. 18. Indeed, the tensile strength $\sigma_{Y}$ had a maximum value at crack tip and decreased gradually as one gets far away from singularity until it reverse near the loading point (it become a compression). This strength is significantly affected by heating temperature. It can be noticed that the increase in the temperature between 25 and $300^{\circ} \mathrm{C}$ would induce an increase in tensile strength $\sigma_{\mathrm{Y}}$. However, beyond $300^{\circ} \mathrm{C}$ the strength decreases. The evolution of the strength $\sigma_{Y}$ ahead of the crack tip of the $15 \mathrm{~mm}$ notch length specimen and for different heating temperatures $\left(100,300,500,700\right.$ and $\left.900^{\circ} \mathrm{C}\right)$ are illustrated in Fig. 19. We point out that the strength ahead crack tip is affected by the notch length $\mathrm{a}_{0}$. An example of $300^{\circ} \mathrm{C}$ heated specimen strength evolution is illustrated in Fig. 20. It appears that the strength rises with the increasing notch length up to $25 \mathrm{~mm}$ value. Beyond $\mathrm{a}_{0}=25 \mathrm{~mm}$, the strength $\sigma_{\mathrm{Y}}$ decreases quasi linearly. 


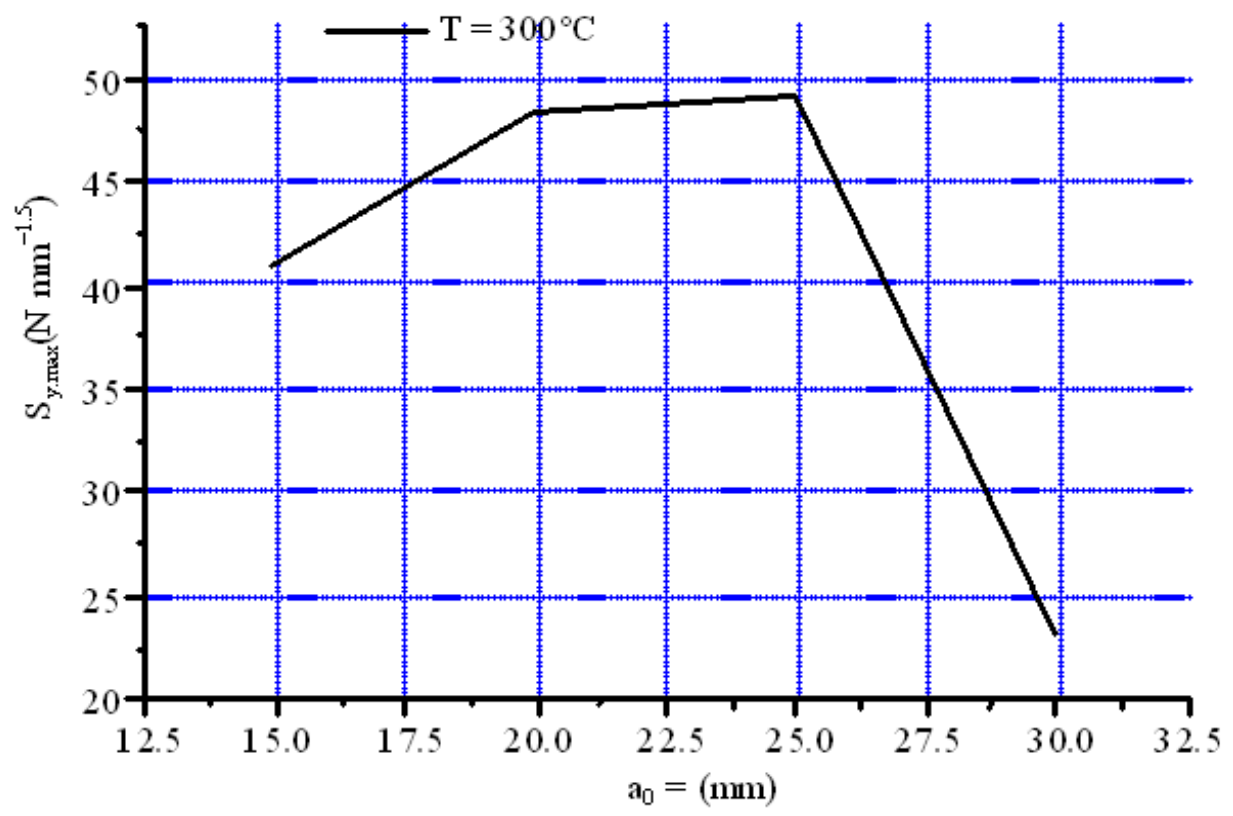

Fig. 20: Maximal strength $\sigma_{\text {Ymax }}$ for different lengths of crack and $\mathrm{T}=300^{\circ} \mathrm{C}$

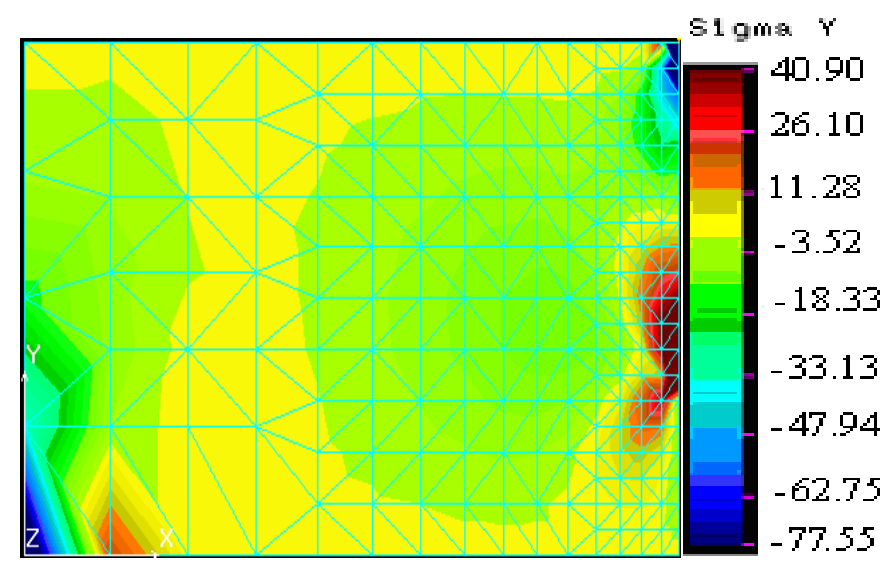

(a)

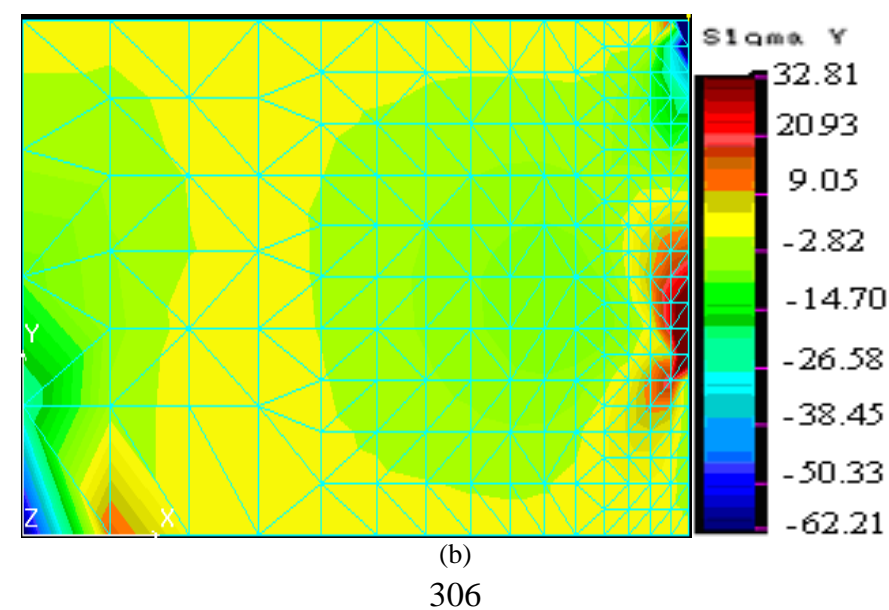




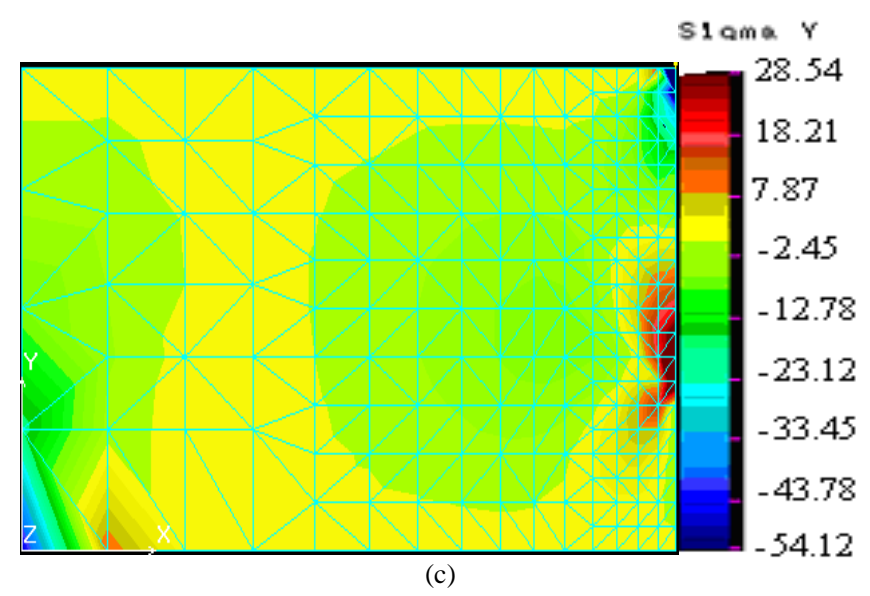

Fig. 21: Strength $\sigma_{\mathrm{y}}$ for $\mathrm{a}_{0}=15 \mathrm{~mm}$, (a) $\mathrm{T}=500^{\circ} \mathrm{C}$, (b) $\mathrm{T}=700^{\circ} \mathrm{C}, \mathrm{c}$ ) $\mathrm{T}=900^{\circ} \mathrm{C}$

\section{CONCLUSION}

The main objective of the present study was the characterization of fracture toughness in opening mode of concrete mortars exposed to elevated temperatures. We have used three-point beams with different notch lengths and at different heating temperatures. Two methods of calculating the fracture toughness using the critical fracture loads were applied: an analytical method based on mechanics of continuous medium and a numerical method by the finite elements code COSMOS M2.0.

The obtained experimental fracture loads are in good agreement with those reported in the literature. Between the room temperature $\left(25^{\circ} \mathrm{C}\right)$ and $300^{\circ} \mathrm{C}$, we recorded an increase of the fracture load. This could be explained by a resumption and acceleration of the cement hydration products which are responsible of the links between the different constituents of the mortar. However, beyond approximately $300^{\circ} \mathrm{C}$, the fracture loads decrease strongly with the rise in heating temperature to vanish at $900^{\circ} \mathrm{C}$. This degradation is related to various phenomena of damage caused by the rise in heating temperature. The fracture toughness calculated by the two methods varies similarly like the fracture loads and this is coherent since they are directly proportional. That is, the same as far as $\mathrm{K}_{\mathrm{I}}$ evolution curves are concerned.

\section{REFERENCES}

1. Hillerborg, A., M. Modeer and P.E. Petersson, 1976. Analysis of crack formation and growth in concrete by means of fracture mechanics and finite elements. Cement Concr. Res., 6: 773-782. DOI: 10.1016/0008-8846(76)90007-7
2. Bazant, Z. P. and M.T. Kazemi, 1990. Determination of fracture energy, process zone length and brittleness number from size effect, with application to rock and concrete. Int. J. Fracture, 44: 111-131. DOI: 10.1007/BF00047063

3. Wittmann, F.H., K. Rokugo, E. Bruhwiler, H. Mihashi and P. Simonin, 1988. Fracture energy and strain softening of concrete as determined by means of compact tension specimens. RILEM Committee 50-FMC, Fracture Mechanics Concr. Mater. Struct. 21: 21-32. DOI: 10.1007/BF02472525

4. Wang, E.Z. and N.G. Shrive, 1995. Brittle fracture in compression mechanisms, models and criteria. Eng. Fracture Mech.. 52: 1107-1126. DOI: 10.1016/0013-7944(95)00069-8

5. Bazant Z.P. and B.H. OH, 1983. Crack band theory for fracture of concrete. Mater. Struct., RILEM, 16: 155-177. DOI: 10.1007/BF02486267

6. GjØrv O.E, S. I. SØrensen and A. Amesen, 1977. Notch sensitivity and fracture toughness of concrete. Cement Concr. Res., 7: 333-334. DOI: 10.1016/0008-8846(77)90096-5

7. Mindess, S. and S. Diamond, 1982. The cracking and fracture of concrete. Mater. Struct., 15: 107-113. DOI: 10.1007/BF02473571

8. Mindess S., F.V. Lawrence and C.E. Kesler, 1977. The J-Integral as a fracture criterion for fiber reinforced concrete. Cement Concr. Res., 7: 731-742. DOI: 10.1016/0008-8846(77)90057

9. RILEM Committee 50-FMC, on Fracture Mechanics of Concrete, 1985. Determination of the fracture energy of mortar and concrete by means of three-point bend on notched beams. Mater Struct., 18: 287-290. DOI: 10.1007/BF02472918 
10. Malvar L.J., E. George Warren., 1987. Fracture energy for three point bend tests on single edge notched beams: Proposed evaluation. Mater. Struct., 20: 440-447. DOI: 10.1007/BF02472495

11. Guo X.H. and R.I. Gilbert, 2000. The effect of specimen size on the fracture energy and softening function of concrete. Mater. Struct., 33: 309-316. DOI: $10.1007 / \mathrm{BF} 02479701$

12. Ouyang, C., T. Tang and S.P. Shah, 1996. Relationship between fracture parameters from two parameter fracture model and from size effect model. Mater. Struct., 29: 79-86. DOI: 10.1007/BF02486197
13. Trunk B. and F.H. Wittmann, 2001. Influence of size on fracture energy of concrete. Mater. Struct., 34: 260-265. DOI: 10.1007/BF02482204

14. Elices M., G. V. Guinea and Planas J., 1992. Measurements of the fracture energy using threepoint bend tests: Part3-Inflence of cutting the P- $\delta$ tail. Mater. Struct., 25: 327-334. DOI: 10.1007/BF02472591 